\title{
Pseudo heroínas: inclusión por exclusión de lo femenino
}

\author{
GI Jane | Ridley Scott | 1997 \\ Eduardo Laso* \\ Universidad de Palermo
}

Recibido: 20 de mayo 2019; aceptado: 9 de julio 2019

\begin{abstract}
Resumen
El film de Ridley Scott G.I. Jane sobre la discriminación de las mujeres en el ejército y su derecho a ser incluidas presenta una solución paradojal: la inclusión de las mujeres es aceptada sólo si ellas eligen renunciar a su femineidad y devienen varones. La teoría freudiana en torno del ejército y su conformación como masa artificial puede ser articulada con el esquema de la sexuación de Lacan del Seminario 20, para advertir que la formación de masa se basa en una lógica masculina que segrega a la mujer para poder creer en la existencia de un Uno de excepción a la castración: el Líder.
\end{abstract}

Palabras Clave: Masa | Género | Castración | Segregación

Pseudo Heroines: Inclusion by Exclusion of the Feminine

Abstract

Ridley Scott's film G. I. Jane about women discrimination in the army and their right to be included presents a paradoxical solution: women's inclusion in the army is accepted only if they choose to resign their feminity and become males. Freudian theory about the army and it's conformation as an artificial mass can be articulated with Lacan's sexual scheme from his $20^{\circ}$ seminary, so as to notice that the mass conformation is based in a male logic that segregates woman in order to believe in the love of One exception to castration: the Leader.

Key Words: Mass Gender | Castration | Segregation

Woman is the nigger of the world, yes she is

If you don't believe me take a look to the one you're with.

John Lennon

Bajo ${ }^{1}$ el título “¿Virilidad o Valentía?”, el historiador Ignacio Lewkowicz publicó en 2001 un artículo sobre el film de Ridley Scott G. I. Jane (1997) -estrenado en Argentina como Hasta el límite ${ }^{2}$. La lectura de Lewkowicz sigue la línea argumental del director, explicitando algunos de sus presupuestos, los cuales nos proponemos abordar desde una perspectiva ético-crítica. ${ }^{3}$

Digamos ante todo que el título del film está construido como un chiste. GI Joees una expresión compuesta por las siglas de Government Issue ("Suministro del Gobierno"), junto al nombre masculino Joe, expresión que designaba, de manera peyorativa, a los soldados norteamericanos durante la Segunda Guerra Mundial. El personaje que encarna Demi Moore no se llama Jane sino Jordan, por lo que el film podría haberse titulado GI
Jordan. Pero aquí se trata de la sustitución del genérico Joe por su femenino Jane, anticipando así el tema del film: el problema de la inclusión de mujeres en el ejército.

Ridley Scott se vale de Demi Moore en el momento de su pico de juventud y de su carrera, para integrarla a un mundo radicalmente diferente al glamourromántico de Ghost (Zucker, 1990), o el erotismo de Striptease (Bergman, 1996), Acoso sexual (Levinson, 1994) o Propuesta indecente (Lyne, 1993). ${ }^{4} \mathrm{En}$ ese momento era la actriz mejor pagada de Hollywood y un sex simbol del cine americano. Para el papel de Jordan ONeill, el realizador inglés no escoge una actriz más versátil pero menos agraciada, como por ejemplo Merryl Streep, porque en ese caso el film sería otro. Scott propone un relato en el que una mujer atractiva se encuentra en medio de un mundo de "machos", como es el universo de los Navy Seals. En otras palabras, Jordan encarna el retorno de algo expulsado del ejército de varones: una mujer sensual que viene a perturbar dicho mundo.

* lasale_2000@yahoo.com 
La trama gira en torno del derecho de las mujeres a integrarse como soldados en el ejército. Sólo que el precio a pagar por tal inclusión consiste en abolirlas en tanto mujeres. En el film (y no sólo allí) el reclamo de igualdad de derechos cívicos y políticos de las mujeres termina solapándose con la diferencia sexual, para recubrirla y reprimirla. La cuestión de género (asunto de identificaciones) y la diferencia sexual se confunden, aplanando el tema de lo femenino tal como es planteado desde el psicoanálisis. El film deviene así una crítica elemental de prejuicios machistas propia del imaginario social asociado al género femenino (como más débil que el varón, como objeto sexual, etc.). Proponemos un desvío por los planteos de Freud (1921) respecto del ejército, y por las fórmulas de la sexuación de Lacan (1981) para reinstalar esta distinción y sus implicancias.

\section{Freud y las masas artificiales}

En el capítulo VI de Psicología de las masas y análisis del Yo (1921), Freud analiza al ejército y la Iglesia en tanto masas artificiales duraderas y altamente organizadas que por sus rasgos y semejanzas son paradigmáticas de cualquier otra formación de masa. Para su época, el planteo debió resultar provocador: el ejército considerado como una masa religiosa, y la iglesia equiparada a una formación militar. De donde se sigue que formar parte de una masa organizada no es muy diferente de estar en el ejército o en una feligresía.

Freud (1921) destaca varios rasgos presentes en ambas organizaciones:

- En ellas opera una coerción dirigida a preservarlas de la disolución y evitar modificaciones en su estructura.

- En general, no depende de la voluntad del individuo el formar parte de ellas. Así, por ejemplo, el bautismo, sacramento que integra a una persona dentro de la comunidad católica, es decidido por la familia al nacer. Y el servicio militar obligatorio viene siendo desde hace años un modo compulsivo de incluir personas en los ejércitos. En Argentina recién se suprimió el 31 de agosto de 1994.

- Dentro de ellas, el sujeto se encuentra sometido a reglas cuyo incumplimiento es castigado.

- Se basan en la creencia en un jefe que ama por igual a todos los miembros del colectivo (Cristo para la Iglesia, el Jefe del escuadrón para el ejército). Esta condición resulta esencial, ya que si cae dicha ilusión, desaparece la masa.

El soldado de un ejército se halla doblemente ligado por lazos libidinosos: al jefe del ejército, y a los otros soldados, que devienen hermanos. Cada soldado ubica al jefe en el lugar de su Ideal del Yo, mientras que su yo se identifica con sus pares, derivando de esta comunidad creada las obligaciones de la camaradería.

La igualdad de los individuos que constituyen estas masas organizadas no abarca al jefe, que ocupa un lugar de excepción. La fraternidad en la masa se constituye desde una desigualdad en torno de un Uno excepcional: son muchos iguales identificados entre sí, que comparten el amor por un único superior en posición de excepción. La masa se configura así como un vínculo de amor entre sus miembros, pero basta la pérdida del jefe para que desaparezcan los lazos que los unen y la masa desaparezca. Como evoca el relato bíblico de Judith y Holofernes. ${ }^{5}$

Ya en Tótem y tabú (1913), Freud postulaba la construcción del lazo social en torno de una función mítica (el Urvater obsceno y feroz), que como tal está vacía, pero por lo mismo es ocupable por cualquiera que reúna ciertas condiciones para advenir a ese lugar.

La segregación es la contracara del vínculo amoroso que configura la masa: el odio, crueldad e intolerancia dirigidos a quienes no reconocen al jefe que encarna el Ideal del Yo. Se trata del rechazo y expulsión de lo ajeno y extraño a la fraternidad, en función de la cual ésta se funda. En el seminario El reverso del psicoanálisis (1992), dice Lacan:

sólo conozco un origen de la fraternidad -quiero decir la humana, de nuevo el humus-, es la segregación (...) en la sociedad, (...) todo lo que existe se basa en la segregación, y la fraternidad es lo primero. Incluso no hay fraternidad que pueda concebirse si no es por estar separados juntos, separados del resto. (p. 121)

Como resume Juan Bautista Ritvo (2011) en Segregación y masa en la polis: "basta que dos cualesquiera se identifiquen con un tercero erigido en líder (...), para que surja inevitablemente un cuarto segregado" (pp. 15-16).

Lo segregado es la contracara de la creencia en el Uno de excepción. En la antigua Grecia existía un rito de purificación, el pharmakos. Cuando ocurría algún desastre, se designaba una víctima que encarnaba el mal de la comunidad. Quien ocupaba el lugar de pharmakon era segregado de la polis, expulsado y hasta sacrificado, por representar una amenaza para la colectividad. Las masas segregan aquello que representa una 
amenaza al vínculo comunitario constituido en torno de un líder idealizado al que se le supone detentor del falo. Como tal, lo segregado encarna una amenaza a este fantasma fálico, en tanto representa todo lo que lo desborda, excede o vacía de consistencia. Aquello que excede al falo encarna el caos, las figuras de lo demoníaco (es decir, lo que se manifiesta de manera contradictoria, imposible, y no puede ser cernido por palabras), el abismo sin fondo, el prójimo como inminencia intolerable de goce en tanto encarnación del objeto $a$. Se trata de una dimensión real, heterogénea y amenazante. Un exceso sin medida. Figuraciones del goce del Otro, que la mujer ha encarnado culturalmente.

El falo es resultado de una metáfora. Pero si una metáfora sustituye un significante por otro, en el caso del falo, lo que viene a sustituir es a una falta. La metáfora paterna produce esta sustitución por lo cual se ubica en el lugar del enigma de la causa del deseo materno al falo como razón del deseo. Al estar en lugar de una falta, el falo va a ser afectado por aquello que sustituye: es una apariencia sin esencia que está donde no está y no está donde está. Se vuelve ubicuo, su exceso denuncia su defecto, y entra como valor agalmático de los objetos en el campo del deseo: pene, niño, heces, dinero, regalo, mujer, etc. En ese sentido, la mujer en tanto encarnación de la diferencia sexual, representa aquello que la premisa universal del falo viene a velar: la falta, el agujero real, el fondo sin fondo al que el falo le pone razón y medida.

Acerca de la diferencia sexual en las formaciones de masa, Freud (1921) plantea: "En las grandes masas artificiales, Iglesia y ejército, no hay lugar para la mujer como objeto sexual. La relación amorosa entre hombre y mujer queda excluida de estas organizaciones. Aun donde se forman masas mixtas de hombres y mujeres, la diferencia entre los sexos no desempeña papel alguno. Apenas tiene sentido preguntar si la libido que cohesiona a las masas es de naturaleza homosexual o heterosexual, pues no se encuentra diferenciada según los sexos y prescinde, en particular, de las metas de la organización genital de la libido". ${ }^{6}$

El lugar de la mujer encarnando el goce materno amenazante y siniestro, es síntoma del fracaso neurótico y cultural del hombre a distinguir y separar madre de mujer. La tara de la sexualidad masculina está ligada en mayor o menor medida a esta dificultad de producir esa separación que nunca es pura y absoluta.
Freud (1921) señala dos obstáculos principales contra la preservación de la formación de masa:

- Las aspiraciones sexuales directas que mantienen parte del quehacer individual y que "si se vuelven hiperintensas, descomponen toda formación de masa” (p. 134). En otras palabras, lo erótico pulsional que insiste como retorno de lo reprimido en cada sujeto.

- El amor por la mujer:

De igual manera, el amor por la mujer irrumpe a través de las formaciones de masa de la raza, de la segregación nacional y del régimen de las clases sociales, consumando así logros importantes desde el punto de vista cultural. Parece cierto que el amor homosexual es mucho más compatible con las formaciones de masa, aun donde se presenta como aspiración sexual no inhibida”. (p. 134)

Freud ubica el amor por la mujer como obstáculo a la masa, a diferencia del amor homosexual, que no la afecta. Apoyándonos en Lacan, entendemos que este es el modo freudiano de hablar del amor dirigido a lo Héteros -lo otro, lo distinto, la diferencia que lo femenino encarna como suplementaria a la lógica fálica- que hace obstáculo a la formación de masa, una formación de Homos, de iguales -cualquiera sea su género- identificados en torno de un mismo amor a un Uno de excepción que, como tal, encarna el padre no castrado de la horda primitiva. Para lo cual se requiere rechazar lo femenino, en tanto cuestiona la ilusión de un Uno de excepción.

\section{Lacan y la sexuación}

Para Lacan (1981) la identidad sexual no es ontológica: no se define en términos presimbólicos de un ser ya dado naturalmente (sea genético, o basado en determinadas características anatómicas). Tampoco es el resultado performativo de un decir sobre el sujeto que parte del Otro (sea familiar o social) que lo determina al designarlo hombre o mujer. El dicho freudiano "La anatomía es el destino" significa que al parlêtre le toca un determinado cuerpo real sexuado, pero no por eso está destinado a identificarse a su sexo anatómico: sobre ese real que le tocó, aún resta que el sujeto responda respecto de la diferencia sexual, para autorizarse varón o mujer. La llamada identidad sexual, que es una identificación, es así resultado de una elección inconsciente no saturable por lo biológico ni por el discurso del Otro. 


\section{FÓRMULA DE LA SEXUACIÓN}

LADO HOMBRE

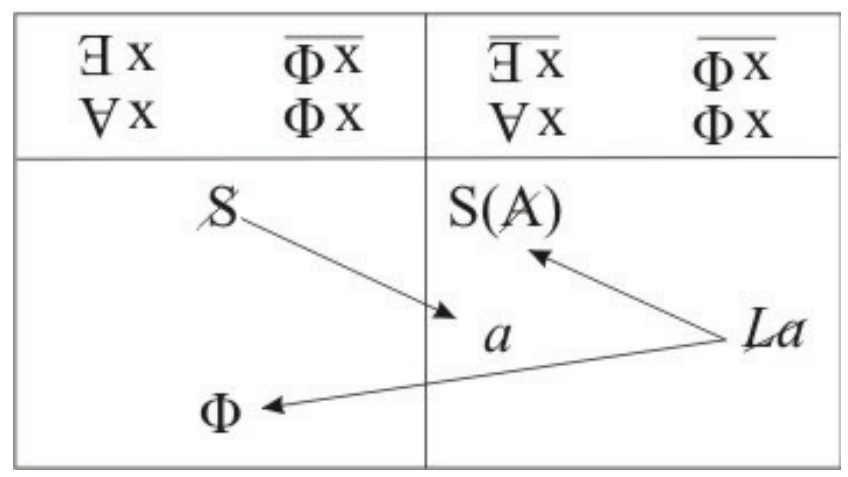

Cualquier parlêtre que haya pasado por las identificaciones que constituyen su cuerpo pulsional, su imagen corporal y la división subjetiva, puede ubicarse en el lado hombre o mujer, con independencia de la anatomía. Lados que no tienen que ver con una clasificación social entre géneros. Ubicarse del lado "hombre" es sostener que hay un Uno de excepción no castrado, respecto del cual se conforma un conjunto de Todos castrados. Ubicarse del lado "mujer" es sostener que no hay Uno de excepción no castrado, por lo que el sujeto queda no-todo saturado en la función fálica ${ }^{7}$ (Lacan, 1981)

En términos del deseo sexual, del lado hombre el parlêtre se dirige al Otro en busca de aquel objeto que haga de semblante de la causa de su deseo, elevado así a valor fálico, no sin la ilusión de tenerlo, otorgada por el partenaire. Del lado mujer, el parlêtre se dirige al Otro buscando el objeto fálico, no sin la ilusión de serlo otorgada por el partenaire, permaneciendo a la vez a cuenta suya un goce suplementario no saturado por el falo: el goce femenino, goce soportado en el significante de la falta en el Otro. "La mujer no existe" significa que del lado "mujer" no es posible armar un todo cerrado en torno de la lógica fálica que agrupe a las mujeres. De un lado al otro, el falo oficia de puente imaginario como apariencia que circula en simulacros sostenidos en los fantasmas de los partenaires. Modo de sostener un vínculo sexual posible tras el fondo de la no relación sexual (Lacan, 1981).

\section{Hasta el límite fálico... pero no más allá}

El ejército como formación de masa es ubicable del lado masculino de las fórmulas de la sexuación, soportado en la creencia de que hay un Uno de excepción no castrado que ama a todos sus miembros. El film de Scott plasma esto en el hecho de que si el derecho de una mujer a incluirse en el ejército finalmente prevalece, es porque lo hará no en tanto mujer, sino en tanto ella se elija del lado varón y rechace lo femenino como objeción al Uno no castrado.

La mujer encarna lo heterogéneo a la masa. De ahí que desde la posición femenina no se pueda estar dentro de ejército, una masa unida que sostiene a un Uno en calidad de líder. La indistinción de la masa, en la que sus miembros son equivalentes e intercambiables, se funda en la distinción de un Amo erigido en Uno no castrado y la expulsión de aquello que lo objete. Se trata de una formación de Homos, que rechaza lo Héteros, en tanto la excepción femenina encarna la objeción a la existencia de un Uno no castrado.

En ese sentido, el problema de fondo no es la inclusión de mujeres en el ejército; el problema es la posición femenina. ¿Las mujeres hacen la guerra en tanto mujeres? ¿O hay algo en dicha posición refractaria a entrar en la lógica especular y totalitaria de "el Uno o el Otro", "vencer o morir"? La guerra es un terreno masculino, no importa si quienes participan de ella son varones o mujeres. Es un terreno en el que se juega la lógica del vel alienante de la ética del héroe trágico, donde la muerte está ubicada a ambos lados de la alternativa.

El film de Scott sostiene que la diferencia sexual es impertinente para la condición de soldado. Es lo que dice Freud (1921), pero porque lo que amenaza la formación de masa es el deseo dirigido a la mujer en tanto aquello que encarna la excepción a la lógica fálica, descompletándola. El ejército ubica como impertinente para la condición de soldado a la femineidad, en tanto ésta inscribe la inexistencia de un Uno de excepción y abre a la lógica del no-todo.

En el ejército, virilidad y virtud militar se equivalen, en una operación ideológica de signo machista. Si algo dice cualquier jefe militar a sus subordinados es que los va a hacer "hombres", en donde soldado y varón serían lo mismo. Al punto que algunos neuróticos vacilantes de su identidad sexual acuden al ejército para reasegurarse como varones. La lógica subyacente es la de la horda primitiva y el temor al padre terrible, del que el jefe admirable que ama es su contracara. Tanta insistencia en la virilidad en un grupo de varones que fraternizan por hacerse amar por un superior, habla de una posición feminizante no confesada. Es el fantasma de "pegan a un niño": soy pegado/amado por mi padre (Freud, 1920). La virilidad no tiene que ver con la masculinidad, sino con un fantasma que gira en torno de un padre falóforo. 
Freudianamente, un hombre es aquel que puede separar la madre de la mujer, no aquel que se hace amar por un padre castrador.

El film de Scott sostiene y prolonga el típico solapamiento entre diferencia sexual real y subjetividad instituida socialmente. Esta última es simbólica, y un recorrido histórico permite estudiar los modos en que las sociedades han intervenido sobre dicha diferencia real de formas diversas: desde el tabú de la femineidad al extremo de la ablación del clítoris, desde la discriminación de los géneros según roles y funciones, modas y hábitos, hasta las políticas de integración de las diversidades sexuales.

No se trata en el ejército de la promoción de la asexualidad -como lo pretendería en cambio la Iglesia, de modo manifiesta y escandalosamente fallido-, sino la necesidad de excluir lo femenino, con independencia de si los integrantes son hombres o mujeres. Si un soldado siente piedad o tiene problemas de conciencia es calificado de "marica" y el entrenamiento ha fracasado. Ningún "no-todo" ni marca de la castración dentro del ejército, que funciona sobre la lógica del todo, quedando la falta expulsada afuera en el "enemigo". ${ }^{8}$

En el film de Scott, la posición femenina es nombrada pity, lástima de sí mismo. La lástima de sí y la lástima por el otro constituyen en el fondo dos aspectos de lo mismo. En el ejército se trata de eliminarla para producir sujetos despiadados. Salvajes. Animales obedientes. Un soldado que sienta piedad por sí mismo o por el prójimo no sería útil para el ejército, que requiere de máquinas obedientes de matar. Pero como la piedad -ligada a la capacidad de empatizar con el semejante- es una consecuencia de la constitución de la subjetividad en torno del Otro materno, se trata de erradicar ese aspecto de lo humano. ${ }^{9}$

En una escena del film la soldado Jordan se ducha mientras aparece su jefe. La cámara se ubica de modo que veamos que éste observa el bello cuerpo desnudo de la actriz. En su comentario al film, Ignacio Lewkowicz (2001) propone leer esta escena en el sentido de una desexualización que el ejército propondría a sus subordinados:

Tenemos que ver a J. O’Neill bañándose. Las miradas van cara a cara, ojo a ojo, sin disculpas, sin vergüenza, sin obscenidad, sin sexo. En ese momento se percibe la potencia de la desexuación necesaria para que nadie sienta lástima de sí. Se trata del momento más delicado. Si se disculpara uno, si se avergonzara el otro, serían todas formas de lástima, y esas son formas inadmisibles para un soldado. (p. 13)

Sólo que lo que vemos es que la soldado O Neill tiene el esplendor del cuerpo de Demi Moore, por decisión del realizador de poner allí a una sex simbol, de manera que nadie pueda dejar de ver ese cuerpo falicizado, ni siquiera el severo jefe de ejército. El tema en esta escena no es la lástima de sí, sino el deseo sexual puesto en juego en una escena de confrontación con la desnudez de una mujer que, como tal, enfrenta al hombre con la diferencia sexual y la ubicuidad del falo. Que los dos personajes guarden las formas de lo que se espera en el ejército no significa que no haya allí tensión sexual entre los personajes, como sutilmente la escena nos muestra. Que en ese contexto eso se silencie, es porque el deseo sexual haría caer al Jefe de su posición, arruinando su lugar de autoridad. Se trata aquí de un ejemplo de simulación donde todos hacen de cuenta que la diferencia sexual y el deseo erótico no contarían. ${ }^{10}$

En un ejercicio militar donde los aspirantes son tomados prisioneros y tienen el deber de no proporcionar información, el jefe de Jordan -en el papel de enemigo- la golpea de un modo más sádico que lo usual para obtener una confesión, al punto de resultar perturbador para los demás compañeros de pelotón. Podríamos preguntarnos: ¿ningún goce aquí colándose en el cumplimiento del deber? ¿Ningún plus a cuenta del disfrute sadomasoquista que el deber militar habilita? No hay allí un tratamiento igualitario, sino un tratamiento "especial" por ser Jordan la mujer atractiva que lo cuestionó en el baño. Cuanto más se trata de rechazar lo femenino que ella encarna, más hay que pegarle. Especialmente si provoca el retorno de sentimientos de ternura y deseo que "ablandan" el temple militar. De ahí que el jefe se pase de límite en la paliza, como síntoma de su temor a la impotencia. En la película como también en la cultura: basta ver el trato que históricamente se les ha dispensado a las mujeres en el mundo por ser fuente de tentación y amenaza de castración.

Cuando Jordan consigue darle una patada en los testículos a su cruel jefe, le grita significativamente suck my dick. Lewcowicz (2001) afirma:

O’Neill le grita: chupame un huevo ${ }^{11}$ Enunciado sumamente interesante, porque los huevos del instructor son la causa de su debilidad. A la vez, que ella diga chupame un huevo significa que ese no es un enunciado de un varón sino de un soldado que habla así, independientemente de su sexo. No es un enunciado de sexuado, es un enunciado de soldado, es un enunciado de desprecio por el miserable que te ha destrozado. (p.15)

Sólo que deberíamos agregar: de una soldado identificada a un lugar masculino. Un enunciado del triunfo imaginario sobre su Jefe, que es, paradójicamente, un triunfo simbólico del Jefe como entrenador: ella se ha 
pasado al lugar de un varoncito. Jordan ha excluido su femineidad para quedar integrada como un soldado más, intercambiable en el seno de una masa artificial al servicio de matar al enemigo.

Ridley Scott construye para Jordan O Neill una subjetividad inconsistente: una mujer bien ubicada en torno de su femineidad... que quiere integrarse en la lógica masculina más radical, como es la de los marines. Estamos ante una fantasía cinematográfica. Más interesante hubiese sido un film donde una mujer quiera integrarse en el ejército persistiendo en su posición femenina, y que ello no cuente como debilidad sino como una fortaleza.

La condición sexual en el film se reprime, para retornar de modos perversos: la obediencia ciega, las prácticas sadomasoquistas, la agresividad desatada, el goce en la subordinación a la autoridad. Ningún ejército forma soldados asexuados, sino "machos", bajo un fantasma viril que se opone a lo pasivo, lo pacifista, lo débil, lo "maricón”, lo femenino, etc., pero que encubre mal la posición femenina masoquista en que se sostiene. ${ }^{12}$

La propuesta del film de Scott es, desde el punto de vista ético-político, una consagración de la ideología militar. Tal vez el tema de Scott sea esa fascinación por dicha lógica. Un cine donde campean las mujeres viriles, como la teniente Ripley de Alien (1979).

Para poner en tensión este pensamiento-cine de Scott, confrontémoslo con Furyo (1983), el film de Nagisa Oshima que propone una tesis más justa de lo que sucede en el ejército con el deseo y el amor. En un campo de prisioneros japonés para soldados británicos durante la Segunda Guerra Mundial, la interacción entre prisioneros y captores abre a vínculos que no son sólo de sojuzgamiento, sino también de amistad, camaradería y deseo. El cruel comandante Yonoi, a cargo de la disciplina en el campo, no puede evitar quedar fascinado por la belleza del coronel Celliers que interpreta David Bowie. Luchando contra ese sentimiento por alguien que no sólo es un varón sino un soldado enemigo, Yonoi va a mostrarse particularmente cruel con los prisioneros. En una escena clave del film, estando por ejecutar personalmente a otro prisionero inglés con su sable, Celliers, que ha comprendido los sentimientos con los que Yonoi viene luchando, sale de la fila de prisioneros para ponerse delante de él y darle un beso frente a toda la soldadesca. Yonoi cae entonces al piso preso de un ataque histérico. Celliers, a su modo, opera como Judith con Holofernes. Sólo que por medio de un beso que denuncia una verdad sobre Yonoi: su amor homosexual, vale decir, su castración. Como consecuencia de lo cual el resto de sus subordinados, desesperados, patean a Celliers hasta desmayarlo. Propongo pensar a Celliers en esta escena como una encarnación de lo Heteros, eso Otro insoportable para la masa del ejército japonés que, al llevar a cabo un acto que pone en juego un más allá de la lógica de la masa militar, logra destituir al comandante de su lugar de Uno de excepción. Como resultado de lo cual Yonoi es sustituido por otro jefe a ocupar el lugar de Uno, y Celliers es enterrado hasta la cabeza y abandonado allí hasta morir.

En G.I. Jane, la defensa de la igualdad de las mujeres basada en que tienen tanto derecho como los varones a volver en bolsas negras como muertas en batalla es una conclusión estremecedora y fascista. Estamos muy lejos de los años sesenta y la defensa que tantas militantes mujeres emprendían a que nadie vaya a la guerra en Vietnam. Ridley Scott realiza un film de derecha jcon mensaje inclusivo! El colmo del fascismo es que puede ocultarse bajo un aparente mensaje en favor del derecho de la igualdad de la mujer. Tiene derecho a ser igual al varón: a matar y a que la maten. Pero no tiene derecho a encarnar la diferencia en tanto mujer. Justamente ese es el punto de horror que la angustia de castración del lado masculino intenta conjurar, velar, rechazar, denegar. "Las mujeres son varones sin pene” es, para esta lógica, preferible a que encarnen la cabeza de la Medusa.

\section{Referencias}

Amigo, S. (2014). La autorización del sexo y otros ensayos. Buenos Aires: Letra Viva.

Bergman, A. (director). (1996). Striptease [cinta cinematográfica]. Estados Unidos: Castle Rock Entertainment.

Caroll, G., Giler, D., Hill, W. (productores) y Scott, R. (director). (1979). Alien[cinta cinematográfica]. Reino Unido: 20th Century Fox, Brandywine Productions.

Churchill, P., Crichton, M., Flamberg, J., Giuliano, P., Levinson, B., Wald, A. (productores) y Levinson, B. (director). (1994). Disclosure [cinta cinematográfica]. Estados Unidos: Warner Bros.

Deeley, M., Fancher, H., Kelly, B., Powell, I., Perenchio, J., Scott, R., Shaw, R., Yorkin, B. (productores) y Scott, R. (director). (1982). Blade Runner [cinta cinematográfica]. Estados Unidos: The Ladd Company, Shaw Brothers, Blade Runner Partnership.

De Laurentiis, D., De Laurentiis, M. (productores) y Scott, R. (director). (2001). Hannibal [cinta cinematográfica]. Estados Unidos: Metro-Goldwyn-Mayer, United Artists, Universal Studios, Scott Free Productions. 
Freud, S. (1913). Tótem y tabú. Obras Completas, Tomo XIII. Buenos Aires: Amorrortu.

Freud, S. (1919). Pegan a un niño. Obras Completas, Tomo XIII. Buenos Aires: Amorrortu.

Freud, S. (1921). Psicología de las masas y análisis del yo. Obras Completas, Tomo XVIII. Buenos Aires: Amorrortu.

Glinwood, T., Hara, M., Herlihy, J., Nethercott, G., Oshima, E., Parr, L., Thomas, J. (productores) y Ōshima, N. (director). (1983). Furyōo [cinta cinematográfica]. Reino Unido: Recorded Picture Company.

Hampton, T., Milchan, A. (productores) y Scott, R. (director). (1985). Legend [cinta cinematográfica]. Estados Unidos: Regency Enterprises.

Jaffe, S.C., Koch, H.W., Weinstein, L. (productores) y Zucker, J. (director). (1990). Ghost [cinta cinematográfica]. Estados Unidos: Paramount Pictures.

Jaffe, S. R., Lansing, S. (productores) y Scott, R. (director). (1989). Black Rain[cinta cinematográfica]. Estados Unidos: Paramount Pictures.

Lacan, J. (1992). El seminario: libro 17: El reverso del psicoanálisis. Buenos Aires: Paidós.

Lacan, J. (1981). El seminario: libro 20: Aún. Buenos Aires: Paidós.

Lansing, S. (productor) y Lyne, A. (director). (1993). Indecent Proposal [cinta cinematográfica]. Estados Unidos: Paramount Pictures.

Lewkowicz, I. (2001). ¿ ¿Virilidad o valentía? Comentario de "Hasta el límite. En J.J. Michel Fariña y C. Gutierrez (Ed.). Ética y Cine (pp. 91-93). Buenos Aires, Argentina: Eudeba.

Pirosh, R. (productor). (1962). Combat! [serie de televisión]. Estados Unidos: Selmur Productions.

Polk Gitlin, M., Scott, R. (productores) y Scott, R. (director). (1991). Thelma y Louise [cinta cinematográfica]. Estados Unidos: Pathé Enterteinment, Percy Main, Star Partners III Ltd.

Puttnam, D. (productor) y Scott, R. (director). (1977). The Duellists [cinta cinematográfica]. Reino Unido: Enigma Productions, Scott Free Enterprises, National Film Finance, Consortium.

Ritvo, J. B. (2011). Sujeto, masa, comunidad. Santa Fe: Mar por Medio Editores.

Ritvo, J. B. (2017). El silencio femenino. Hacia (desde) la filosofía. Buenos Aires: Nube Negra.

Saccomanno, G. (2008). Bajo Bandera. España: Booket.

Scott, R. (productor y director). (1997). G.I. Jane [cinta cinematográfica]. Estados Unidos: Caravan Pictures.

Scott, R., Golbacas, A. (productores) y Scott, R. (director). (1992). 1492: Conquest of Paradise [cinta cinematográfica]. Reino Unido: Due West.

Scott, R., Hill, W., Giler, D. (productores) y Scott, R. (director). (2012). Prometheus [cinta cinematográfica]. Estados Unidos: Scott Free, Brandywine Productions.

Spielberg, S., Bryce, I., Gordon, M., Levinsohn, G. (productores) y Spielberg, S. (director). (1998). Saving Private Ryan [cinta cinematográfica]. Estados Unidos: Mark Gordon Productions, DreamWorks, Paramount Pictures, Amblin Entertainment, Mutual Film Corporation.

Wick, D., Franzoni, D., Lustig, B., MacDonald, L., Needham, T., Parkes, W.F., Scott, R. (productores) y Scott, R. (director). (2000). Gladiator [cinta cinematográfica]. Estados Unidos: Scott Free Productions.

Zupancic, A. (2013). La sexualidad dentro de los limites de la mera razón, Santiago de Chile: Palidonia.

1 Una versión preliminar del presente trabajo fue presentado por su autor en las Jornadas "La cuestión de la persona: Análisis $\diamond$ masa” de la Facultad de Ciencias Sociales de la Universidad de Palermo, Cátedra Modelos y Teorías IV Psicoanálisis Lacan, el 28 de Junio de 2019.

2 El texto de Lewkowicz apareció originalmente en el volumen colectivo Etica y Cine, Michel Fariña, J. y Gutiérrez, C. (Ed.). Eudeba, 2001. Fue republicado en Aesthetika, V. 4, N², pág. 13-15. Disponible en línea en: http://aesthethika.org/Virilidad-o-valentia

3 Como veremos más adelante, una ética que vaya más allá del vel alienante del héroe trágico.

$4 \quad$ El director inglés Ridley Scott es un buen artesano que carece de un mundo propio o un mensaje particular a transmitir. No hay un centro temático u obsesión particular entre Los duelistas (1997), Alien (1979), Blade runner (1982), Leyenda (1986), Thelma y Louise (1991), 1492: la conquista del paraiso (1992), etc. Realizó tres películas notables (Los duelistas, Alien y Blade Runner), algunos films logrados (Thelma y Louise, Black Rain (1989)) y una larga serie de films intrascendentes, más allá del éxito de taquilla (1492, Gladiator (2000), Hannibal (2001), Prometeus(2012) que fueron defraudando las expectativas depositadas en él. Baste recordar, su director's cut de Blade Runner, versión “corregida” de un film que rozaba la perfección, que modifica la propuesta ética original: no es lo mismo que Rick Deckard sea o no un "replicante” a los efectos de evaluar el último gesto de piedad del replicante que en- 
carna Rutger Hauer. De acto ético que lo vuelve conmovedoramente más humano que los humanos que lo quieren matar, a gesto particularista de no matar a Deckard por ser uno de los suyos.

5 Para un argentino que cumplió el servicio militar obligatorio, resulta extraño el planteo: nadie que haya pasado por esa experiencia forzada ha sentido nunca el amor por su jefe de escuadrón o batallón. Ningún Sargento Sanders de la vieja serie Combate (Pirosh, 1961), ningún “comandante” alla Che Guevara por el cual dar la vida, ningún entrañable capitán Miller de Rescatando al soldado Ryan (Spielberg, 1998). Sólo una cadena de autoridades arbitrarias, violentas y soberbias que se ensañaban con los soldados, reducidos a la función de "colimbas" para cebar mate, trapear pisos y hacer guardias. Mundo miserable que tan bien supo retratar Guillermo Saccomanno en la novela Bajo bandera (1991). Tal situación se explica por la influencia de la tradición prusiana en el ejército argentino, del cual Freud dice que el descuido del factor libidinoso constituye un peligro práctico para un ejército:

El militarismo prusiano, tan «apsicológico» como la ciencia alemana, quizá debió sufrirlo en la Gran Guerra. En efecto, en las neurosis de guerra que desgarraban al ejército alemán pudo discernirse en buena parte unas protestas del individuo contra el papel que se le adjudicaba en el ejército; (...) el trato falto de amor que el hombre común recibia de sus superiores se contó entre los principales motivos de contracción de neurosis. (Frend, 1921, pp. 90-91).

6 Freud, S.; "Psicología de las masas y análisis del yo” (1921), en Obras Completas (1975), Buenos Aires, Amorrortu, Tomo XVIII, pág. 134 .

7 A todo ser que habla, sea cual fuere, esté o no provisto de los atributos de la masculinidad -aún por determinar- le está permitido, tal como lo formula expresamente la teoría freudiana, inscribirse en esta parte. Si se inscribe en ella, vetará toda universalidad, será el no-todo, en tanto puede elegir estar o no en $\Phi \xi$. (Lacan, 1981, p. 97).

$8 \quad$ Al enemigo sí se lo puede eventualmente tomar como objeto de goce sádico. De ahí la necesidad de leyes dentro del ejército que prohíben esas explosiones de exceso a las que las masas del ejército son tan propensas en circunstancias de guerra.

9 En su texto ¿Virilidad o valentía? a propósito del film de Scott, Ignacio Lewkowicz (2001) señala sobre el entrenamiento militar que padece la soldado Jordan: "La subjetivación consiste en producir una subjetividad que no se apiade y esa subjetivación es por vía poética. Ese entrenamiento militar salvaje es poesía pura, no es romanticismo” (p. 13), aludiendo a la sorpresa final del film, en la que Jordan descubre que las palabras que imparte su severo Jefe de escuadrón son una cita culta de un poema de D. H. Lawrence. Si por poesía entendemos poiesis al modo griego, es decir, "producción”, entonces vale la referencia, en tanto se trata de producir seres despiadados. Pero en el sentido de "poesía” como producción estética sublime en torno de la falta, el film de Scott pone a Lawrence (como antes puso una imagen del mismo militar leyendo a Coetzee) para hacer la operación fascista de estetizar la guerra, y así legitimar ideológicamente la eliminación de la piedad y la renegación de la falta que la femineidad encarna. Se trata de hacer pasar por sublime el proceso de supresión en un sujeto de su tendencia a empatizar con el otro para ir más allá de las barreras del bien y la belleza como límites ante un goce mortífero, comandado por una voz de mando en función superyoica.

10 De paso, cabe preguntarse: ¿ninguna violación en grupo a mujeres soldado en los cuarteles? ¿Ningún homoerotismo entre los muchachos? En un universo cerrado de hombres, ¿se puede afirmar que no está presente la sexualidad bajo la forma de la crueldad sádica? Basta atender a las expresiones de los soldados para que pueda escucharse toda la fantasmática de la penetración y de la polaridad macho/hembra que éstas vehiculizan. Por no mencionar lo que sucede cuando los soldados van al frente de guerra y se "sacan las ganas” en nombre de la patria con la población civil del enemigo de turno.

11 Interesante error de traducción por parte del autor: ella no habla de huevos sino de pene, lo cual es bien distinto a los efectos de la argumentación aquí esgrimida.

12 Si hay una formación de masa en Occidente con pretensiones de que la sexualidad caiga -sin que lo logre, como es de público conocimiento- es en la Iglesia Católica entre los sacerdotes y las monjas. 